\title{
O ESPAÇO: INTEGRAÇAO E SENTIDO INVESTIDO EM "BOM CRIOULO" "
}

\section{Rosse Marye Bernardl on}

Em Bom Crioulo estamos diante de uma obra em que a função da descrição foge a um papel puramente decorativo, para impor-se como uma força explicativa e simbólica.

Há no romance uma atenção pormenorizada pelo ambiente, lugares c paisagens que tenderão a "revelar e justificar a psicologia dos personagens, dos quais são ao mesmo tempo signo, causa e efeito". 1

A relaçāo do espaço assume, portanto, enorme importância, seguindo a tradição do romance realista-naturalista, valorizando o ambiente. elemento literário da descriçāo. O narrado está diretamente vinculado à espacialização, considerada como ponto de origem e confluência dos acontecimentos, dada a importância com que se considera o momento e o ambiente sobre os destinos humanos.

Estruturalmente, a obra, cuja temática explora a perversāo sexual entre os marinheiros, tem o seu espaço circunscrito aos ambientes que propiciam maior autenticidade ao narrado. Assim temos praticamente três espaços fortes:

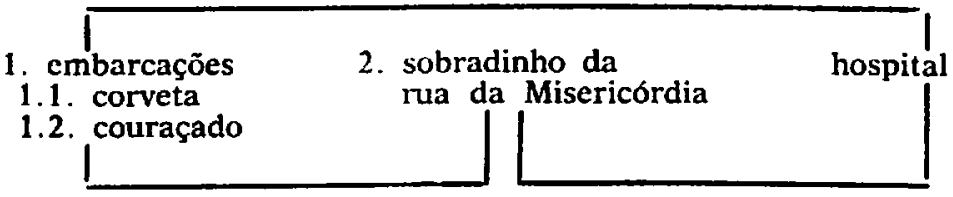

Topologicamente, estes três espaços, unidos entre si pelo ambiente miserável das ruas que circundam o cais. delimitam a vida do

* Trabalho elaborado como Monografia para conclusåo do Curso de Especla. lizaça de Literatura Brasileira tendo obtido o grau 9 (nove) por parte da Prof. Cassiana Lacerda Carollo, Coondenadora do Curso.

* Auxiliar de Ensino de Literatura Brasileira na Universidade Federal dr. Paraná. publicou no número 23 da revista Letras Os motivos: suportes estru. turals em Rainas vivas, romance gaucho e em Arquivos (v. 2, no 4), José de Alencar: lusofobin ou valorizaç̆o do homem portugués?

1. GENETTE, Gerard. Fronteiras da narrativa. In: ANALISE estrutural da uarrativn. 2. ed. Petrópolis. Voaes, 1971. p. 265. 
Bom Crioulo, personagem principal, forjam e decidem o seu destino e todos cles podem ser considerados, quanto ao modo de descrição, como espaços signos, altamente funcionais. remetendo a ambientes psico-sociais. Fugindo ao clichè do pano de fundo, à concentração descritiva estática, os espaços formam ao mesmo tempo uma topologia e uma tópica do discurso dramático. Tecnicamente poderíamos falar de um lugar que é o próprio espaço da representação e de uma tópica deste lugar, isto é. a cena. a se falar e a agir sobre os personagens.

Esquematicamente teríamos:

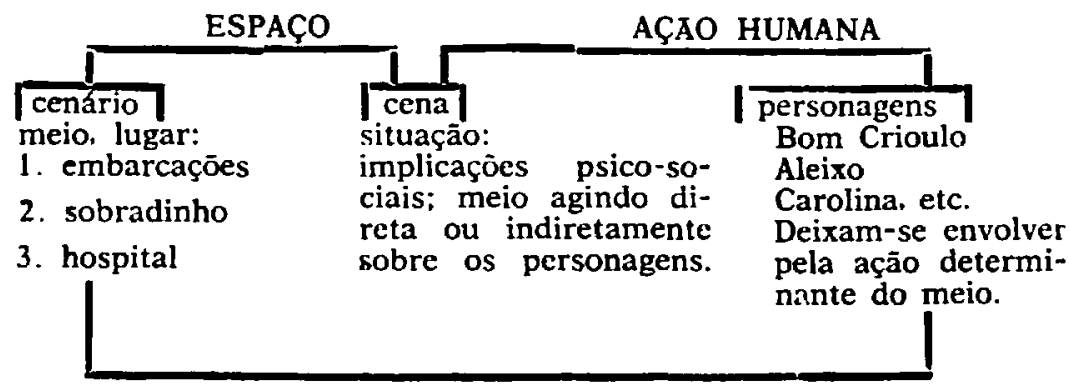

O gráfico acima vem salientar o valor da cena, meio termo complexo entre a açāo humana (a narraçāo) e o cenário (o espaço narrado), numa abertura para um novo ponto de convergência do sentido. de uma nova codificaçāo possível do espaço. No discurso. este preenchido pela descrição. numa sucessão ininterrupta de imagens que se revelam por intermédio de sons. cores, odores, linhas e pelo estado de tensão que transparece em formas sensíveis, avultando plenamente em seu fundo ideológico, estabclecendo uma relação de instituiçāo scmântica quanto à sua leitura, que se estabelece em termos da dependência do homem ao meio que o circunda.

Importa ainda observar que:

"as descrições que ocupam uma funçāo diegética importante situam-se já no início da narrativa ou nos capitulos imediatos e vem a ser uma modalidade adotada por todo romance que pretende analisar a ação determinante do meio sobre o personagem". 2

1. Com relação ao item "embarcações" torna-se necessária uma subdivisão. em termos das diferenças ambientais e das reaçōes psíquicas diversas que elas provocam, estabelecendo diferentes situaçöes e comportamentos:

1.1. A corveta - primeiro espaço representado pela descrição, sobressai-se quantitativamente e é a base para o elemento dramático. O capítulo inicial apresenta-a já num aspecto de decadència. salien-

2 aguiar E silva, victor Manuel de. Teoria da literatura. 3. ed. Coimbra. Almedina, 1973. D. 288 . 
tando através de metáforas c outras imagens comparaçōes entre o passado e o presente da embarcação:

outrora

"galera de lenda branca e leve"

"enorme garça branca"

"esplêndido aspecto guerreiro" agora

"sombra fantástica de um navio".

"esquife agourento" (imagem repetida à p. 52 "velho esquife").

"grande morcego apocalíptico de asas abertas sobre o mar". 3

Tais imagens, manipuladas pclo narrador numa distância estética manipulada a priori, sobrelevam-se $\mathrm{cm}$ termos de relacionamento com a vida animal nos termos "garça" e "morcego", ao mesmo tempo que abrem uma possibilidade comparativa com a vida orgânica que a embarcação carrega no seu interior. Em ambos há um evidente processo de entropia e decadência física que se cristaliza na passagem do tempo: a garça se transforma em morcego e o "esquife agourento" prenuncia que seu carregamento tanto moral como fisicamente se destruirá e se decomporá por uma conseqüència natural.

Ao retrato físico do personagem principal, o negro Amaro, antecede-se uma descrição exata da corveta, não apenas enquanto lugar, mas envolvendo aspectos de situaçăo. E tudo é sentido muitas vezes através da sugestão, do movimento, da agitação, dos castigos físicos - e deste conjunto todo resulta a impressão de uma desconsolada miséria, sendo que, juntamente com a descrição material, sugere-se também a atmosfera moral, densa e sombria, que prenuncia o crime e o vício, tornando verossimeis as açōes e as vidas evocadas: oficiais deturpados pelo mando, marinheiros cuja integridade moral é destruída por uma disciplina cruel:

Um frêmito de instintiva covardia como uma corrente clétrica, vinha à face de toda aquela gente abespinhada ali [...]. Era um respeito profundo chegando às raias da subserviência animal que se agacha para reccber o castigo, justo ou injusto, seja ele qual for 4.

Desta forma, o ambiente se liga diretamente à fatalidade do destino de todas aquelas miseráveis vidas. $\mathrm{E}$ a própria aparência de Bom Crioulo está vinculada a este ambiente, pois à força da chibata suas costas tornaram-se férreas. indiferentes ao castigo físico.

3 CAMINHA, Adolfo. hom crioulo. Rio de Janelro, Ollve Ed., s,d. p. 7. 4 CAMINHA, p. 12. 
Através da descrição sugere-se uma harmoniosa dependência entre a pessoa do negro Amaro/o espaço em que se encontra e/a vida que leva:

A força nervosa era nele uma qualidade intrínseca sobrepujando todas as outras qualidades fisiológicas [...] Esse dom precioso e natural desenvolvera-se-lhe à força de um exercício continuado que o tornara conhecido $\mathrm{cm}$ terra $[\ldots]$ e a bordo quando voltava embriagado 5 .

A sua pujança fisica se desenvolvera na Marinha e no trabalho escravo anterior, ao mesmo tempo que o ambiente produzira toda a fraqueza moral, desregramentos e taras, tornando-o uma criatura puramente instintiva. despertando perversōes genćticas e um total desconhecimento do bem e do mal. Amaro chega à Marinha como negro fugido e "seu caráter era tão meigo que os oficiais começaram a tratá-lo por Bom Crioulo". 6

No entanto, depois de longas viagens, transforma-se totalmente, dominado pela maioria. As açōes e gestos doces e tolerantes transformam-se $\mathrm{cm}$ agressividade $\mathrm{e}$ insubmissão, comprovando assim a tese da unidade do estilo do meio, na qual sāo incluídos também os seres humanos. Através de situaçōes penetrantes e sugestivas. o narrador levanta, na defesa de sua posição, a significação sociológica-moral dos instrumentos, das peças do navio, possibilitando determinar os elementos não apresentados através dos que foram descritos.

Particularmente também o navio se prende a uma espécie de signo da própria vida do Bom Crioulo que se "divertia a construir pequenas cmbarcações de madeira imitando navios de guerra [...] com a paciência tenaz de um arquiteto". $\bar{T}$

Conforme Bachelard, "as casas en miniatura sāo objetos falsos providos de uma objetividade psicológica verdadeira". 8 o fato do personagem miniaturiar o navio, numa fase em que psicologicamente o seu sonho e esperança nele se resumiam. colocam-no numa posiçāo de aparentemente possuir em potencial, o mundo potencial, o mundo desejado nas mãos, isto no sentido shopenhaueriano de que o mundo é a nossa imaginação.

Por outro lado, em termos de identificação homem/lugar, deparamo-nos com uma situaçāo de topofilia: na fase inicial, o navio é a casa sonhada, a casa em liberdade, é o próprio universo. E como motivação a miniatura não está colocada gratuitamente no texto. podendo ser lida inclusive numa inversão de polos:

5 CAMINHA, p. 21.

6 Ibld., p. 38.

7 Ibld., D. 29.

8 Bachelard. Gaston. A postica do espaco. In: OS PENSAdores. Sãu Paulo, Abril Cultural, 1954, v. 38, D. 452. 
- Na imaginação do homem, ex-escravo, o navio representa o mundo livre;

- na realidade, o navio. enquanto organização social, verdadeiro cosmos flutuante, representa imposiçōes e a destruiçāo desta liberdade, pois, segundo a tese defendida, é o ambiente que modifica o homem e nunca o contrário.

Assim, organicamente, a embarcação, nas implicações psico-sociais do seu espaço, vai decidir o destino de Bom Crioulo, de forma que podemos compreender aqui como a descrição navio-Bom Crioulo se integram semanticamente, devendo o primeiro ser visto como um epicentro e também como a metáfora da personagem. Isto é: como a embarcação, também o negro Amaro tem o seu momento de pujança e plenitude física, mas depois ambos começam a se desgastar. a se deteriorar. No entanto, enquanto a corveta vai para o dique. numa tentativa de recuperação, para Bom Crioulo há apenas o fatalismo de uma irremediável decadência moral e física:

Um desespero surdo, um desespero incrível, aumentado por acidentes patológicos, fomentado por uma espécie de lepra contagiosa [...], um desespero fantástico enchia o coração amargurado de Bom Crioulo 9.

E também o navio que propicia, com a sua intimidade entre os marinheiros, a aproximação Bom Crioulo/grumete Aleixo. Para o negro este conhecimento é a revelação do corpo - a grande preocupaçāo naturalista, e a fatalidade de sua natureza cai sobre ele como uma força inexorável. A patologia sexual passa a ser denunciada e indiretamente criticada.

De forma elementar, inicialmente Bom Crioulo "revolta-se contra semelhante imoralidade que outros de categoria superior praticavam ali mesmo sobre o convés". 10 Mas vence o instinto e se concretiza a problemática do vício sexual, apresentado ao mesmo tempo como social e fisiológico. Isto nos prova como o espaço vincula-se diretamente ao comportamento humano, dentro de uma visão ideológica específica e daí, como já dissemos anteriormente, a preferência pelos ambientes viciosos que levam à consumação dos delitos, abolindo qualquer drama moral. Bom Crioulo sente-se:

Justificado perante sua consciência, tanto mais quanto havia exemplo ali mesmo a bordo [...] Se os brancos faziam, quanto mais os negros! E que nem todos podem resistir: a natureza pode mais que a vontade humana 11 .

Entre os ambientes descritos do interior do navio, toma vulto o

9 CAMINHA, p. 162.

10 Ibid., p. 43.

11 Ibid., p. 62. 
porāo, onde o drama murado dos marinheiros cresce, avolumando as causas do mal estar e da concuspicência. E um lugar fétido, cheirando a urina e alcatrão. em cuja escuridāo concretizam-se coisas inconfessáveis. O porāo é, portanto, um dos polos de verticalidade do navio/casa/mundo. O outro polo, conforme observado por Bachelard 12 seria o sotāo. aqui representado pelo convés. De certa forma, o porāo corresponde à irracionalidade e explosāo das baixczas humanas. "E 0 ser obscuro" - "o ser que participa das baixezas subterrâneas", 13 que proliferam como larvas no intimo do navio e dos homens.

Já o convés com a sua abertura representa a verticalidade, propiciando o sonho sem limites. Assim é que do convés o narrador parte sempre para a descriçāo de imagens marinhas ou de alvas. Mas cstas imagens, que poderiam ser consideradas como clichês, são também mencionadas com intenção, já que favorecem uma simbologia de liberdade para o ex-escravo:

Todo o conjunto da paisagem comunicava-lhe uma sensação tão forte de liberdade e vida, que até lhe vinha vontade de chorar [...]. Aquele magnifico cenário gravara-se-lhe na retina para toda a existência; nunca mais o havia de esquecer. 6 , nunca mais 14 .

O mar transforma-se na imagem obsedante da liberdade sem entraves. Bom Crioulo deita-se no convés. sentindo sensações inimagináveis: "A grandeza do mar enchia-o de coragem espartana. Ali se achava, ao redor dele, a sublime expressão da liberdade infinita".15

Há ainda um relacionamento continuo entre sensaçōes e paisagens vistas ou lembradas, estabelecendo a dialética do interior/exterior. E assim que o negro Amaro relembra seus antigos companheiros do eito. envoltos na fumaça tênue e longinqua da lembrança dos cafezais, na opressāo de um passado que quer esquecer. $O$ contraponto a estas imagens da escravidāo está sempre no mar azul crivado de embarcações.

Em outras circunstâncias, apresentam-se algumas descriçōes que fazem da paisagem marinha uma espécie de "écart" romântico: "A lua surgindo lenta e lenta [...] misto de névoa e luz, alma de solidāo, melancolizava o largo cenário das ondas". 16

Pelo que foi abordado neste primeiro item, fica implicito que a corveta, enquanto lugar e instituiçāo. estabelecendo um sistema de vida com todas as suas implicaçōes. integra-se num espaço maior, que é o mar. num simbolismo facilmente identificável. Assim. para

12 BACHELARD, p. 366.

13 Ibid.. D. 367.

14 CAMINHA, p. 27.

15 Ibid., p. 32.

16 Ibld., p. 63 . 
Bom Crioulo, a trilogia corveta/mar/Aleixo, traduzidos em Casa/Liberdade/Amor, cstabelecem, além de toda e qualquer crítica em termos ideológicos que possamos levantar, uma situação de topofilia.' $\mathrm{Na}$ integração dos três elcmentos está a imagem da felicidade, apresentada nos devancios oníricos da personagem:

Desejaria que a viagem se prolongasse indefinidamente, que a corveta não chegasse nunca mais, que o mar se alargasse de repente submergindo ilhas e continentes numa cheia tremenda, e a velha nau, só ela, como cousa fantástica, sobrevivesse ao cataclismo, ela somente, grande e indestrutivel, ficasse flutuando, flutuando por toda a eternidade 17.

Como se observa, os espaços acima situados se integram perfeitamente en imagens que poderiamos chamar primordiais, ligando-se inclusive a certos mitos, como o do dilúvio. com as suas implicações de renascimento ou de uma nova vida, estabelecidas inconscientemente e de maneira instintiva no negro Amaro.

1.2. Couraçado. Contrapondo-se ao espaço da corveta, de onde é transferido contra a vontade, o couraçado de grande porte faz o Bom Crioulo sentir-se numa prisão de aço. Nāo há sensação de identificação, mas de desiquilíbrio, verdadeira topofobia. Não é mais o seu mundo, congregando o ser e objetos conhecidos e amados, mas é um ambiente de ódios recíprocos, indice de situaçāo que faz precipitar os acontecimentos. Pressionado pelo ambiente. Bom Crioulo foge do couraçado ao encontro de Aleixo. Este, porém, já fora também influenciado por outro ambiente, o do sobradinho, implicando na sexualidade feminina da portuguesa Carolina.

Para o negro Amaro não há mais, portanto, um lugar de identificação. Não mais se integrará a espaço algum. Sua situaçāo é a de um pária - só, esquecido, odiado. em desconforto em qualquer ambiente.

2. O sobradinho da rua da Misericórdia é também um espaço signo cuja descrição remete igualmente a um ambiente psico-social.

A casa é sórdida e miserável, reduto de uma prostituta que alugava quartos somente a pessoas sem qualificação, "gente que não se fizesse de muito honrada e de muito boa". 18

E num quarto do sotāo, na trapeira, que Bom Crioulo se instala com Aleixo, e com suas pessoas transferem-se todos os vícios adquiridos no navio. Transformando-se num amontoado de bugigangas $\mathrm{e}$ na atmosfera da realização sexual, a trapeira será a extensão do próprio ambiente pervertido da embarcaçāo. E o ar de bazar hebreu, de

17 CAMINHA, p. 40-1.

18 Ibid., p. 70. 
sujeira, o mau cheiro que sāo caracteristicas do pequeno quarto, passam a configurar a própria imagem do negro Amaro, representando-o metonimicamente aos olhos do Grumete Aleixo, quando este consegue libertar-se da sua influência.

O ambiente do sobradinho todo ele rescende a um aspecto de luxuriante perversāo, casando-se também com a imagem da dona da casa. Além da trapcira, onde se confina a pederastia, há a reserva da alcova da portuguesa Carolina, reduto dos amores de vários homens. Como elemento significativo do seu espaço há a porta da alcova, permitindo, através da sua semi-abertura, distinguir a intimidade: a cama, gestos sensuais, a nudez disfarçada, elementos através dos quais Carolina inicia o processo de sedução de Aleixo. Também a porta da trapcira carrega uma poderosa significação. Como a ou. tra, cla protege o privado do público, a luxuria dos olhos alheios: "Bom Crioulo dava volta na chave por via das dúvidas". $19 \mathrm{E}$ é encontrando pela primeira vez a porta do quarto fechada, índice da ausência do negro. que Aleixo começa a libsrtar-se de sua influência.

E quando a porta do quarto de Carolina se abre totalmente para a entrada do grumete. numa nova experiência sexual - a trapcira transforma-se "num lugar de maldiçōes: vivia trancado a chave, lügubre e poeirento." 20

$\mathrm{Na}$ oposição da porta que se abre abre e da porta que é fechada há, para o casal Carolina/Aleixo, um passado a esquecer e um pre. sente a ser vivido: um fim e um novo começo. Metaforicamente há também um jogo múltiplo de vida e morte. Fechando a porta a Bom Crioulo. Aleixo abriu-a para seu próprio fim. Não haverá mais encontros íntimos entre eles e a decisāo inevitável se dará no palco das ruas.

Além da porta. outro elemento importante é a janela, abertura para o espaço exterior. A jancla do sobradinho dá para a rua da Misericórdia e é. uma espécie de limite e um liame entre o interior da casa e os acontecimentos externos. E da janela que Carolina, depois do crime, observa passar Aleixo "nos braços de dois marinheiros, levado como um fardo, o corpo mole, a cabeça pendida para trás." 21

3. O terceiro espaço forte é o hospital, situado no topo da ilha. Bom Crioulo, depois da fuga do couraçado é preso e levado para este ambiente de opressão, que funciona como um prenúncio de sua vida futura. Ali ele desenvolve suas mágoas interiores e a dissolução de sua pujança física: "alimentando-se parcamente. ouvindo a toda hora gemidos que entravam na sua alma como uma salmodia agourenta." 220 peso da solidão enche-o de desespero, aumentado por

19 CAMINHA, p. 78.

20 Ibid., p. 148.

21 Ibid.. D. 186.

22 Ibid., D. 134. 
acidentes patológicos. Sente o hospital como uma prisāo que age sobre ele condicionando a revolta e o crime. A fuga é a decisão fatal.

o espaço das ruas é um espaço aberto, mas também corrosivo. E o espaço da fuga, o seu caminho, e também o liame entre um espaço e outro. Representa o próprio signo da violência, proliferação da misćria, que concentra o olhar da curiosidade pública. Em todos os outros espaços o vício í camuflado e protegido, mas aqui. nas ruas, há o espetáculo do qual todos participam através de portas e janelas.

A ação dramática concentra-se no trajeto que vai do cais ao sobradinho da rua da Misericórdia, caminho da própria fatalidade. Ali situam-se as vendas onde o Bom Crioulo bebe a cachaça que o transforma num animal. E o espaço das desavenças, das lutas corporais e das prisões sofridas pelo negro. E também o palco em que se situa a cena do assassinato de Aleixo, magistralmente descrita. O horror da morte é sugerido através de verdadeiros flashes que se deslocam do desespero de Aleixo debatendo-se nas mãos de Bom Crioulo, ao movimento da multidão, às janelas que se abrem. "Forma-se um grande círculo de gente ao redor dos dois marinheiros" 23 e quando se afastam já o grumete jaz ensanguentado, realizando a morte que se disscminara pelo espaço romanesco de forma implícita.

Através do que foi levantado, cremos ter deixado claro o sentido de que se investe a descrição dentro da narrativa. Ao abolir de todo o aspecto puramente ornamental, para se tornar significativa, a descrição dá ao espaço um sentido integralizador, ligando-o intimamente às experiências humanas, numa relação evidente de causa e efeito. o espaço torna-se signo, indice e agente propulsor de condutas.

De maneira geral, se considerarmos as obras que se filiam à estética naturalista, teremos $\mathrm{cm}$ mente que elas não apresentam um reflexo exato e objetivo da realidade objetiva, mas uma deformação estabelecida pela cosmovisão do cientificismo do século XIX. Mas Bom Crioulo não chega a ser radical com relação aos postulados da escola. Considera o indivíduo como resultante do choque entre a hereditaricdade que forma o temperamento e a sociedade que condiciona a conduta, mas demonstra a sua tese sem estabelecer dogmas didáticos e sem ser prolixo.

A narrativa é sempre harmoniosa e de certa maneira consegue vencer os exageros $c$ as deficiências da escola. Na relação espaço/ conduta humana, as reaçōes das personagens não são exageradamente mecânicas nem tão evidentes os fíos que as conduzem.

O problema ãa perversão sexual é apresentado mais como problema de meio que de hereditariedade. 0 espaço do navio, ambiente exclusivamente masculino í convincente para condicionar as práti-

23 CAMINHA, p. 185. 
cas sexuais anormais. Ao se transferir de um lugar para outro, Bom Crioulo leva consigo elementos que propiciam anormalidade. No relacionamento Bom Crioulo/Aleixo, vemos que é o primeiro que carrega o estigma da perversāo identificado pelo meio. Já Aleixo é normal, levado ao vício pela força exclusiva do ambiente e por não conhecer o lado normal da sexualidade.

Enfim, há em toda a narrativa, forte, ousada, repulsiva às vezes, uma enorme grandeza, captada principalmente na evoluçāo do negro Amaro, cujas ações e destino são convincentes, sendo o seu sentido perfeitamente integrado no espaço descrito.

\section{HEFERENCIAS BIBLIOGRAFICAS}

agular E SILva, victor Manuel de. Teoria da literatura. 3. ed. Colmbra Almedina, 1975. $769 \mathrm{p}$.

ANALise estrutural da narrativa. 2. ed. Petrópolis, Vozes, 1971. 285 p.

Bachelard, Gaston. A poética do espaço. In: CS PENSAdores. Săo Paulo. Abril Cultural, 1974. צ. 38, s. 158.512.

CAminha, Adolfo. Bom crioulo. Rio de Janeiro, Olivê Ed., s.d. 187 p.

\section{Resumo}

Estc trabalho visa o estudo do espaço na obra Bom Crioulo, de Adolfo Caminha, na tentativa de demonstrar a sua objetividade e funcionalidade. Assim foram levantados très espaços fortes: as cmbarcaçōes, o sobradinho da rua da Misericórdia e o hospital, os quais funcionam como delimitadores e elementos decisivos na vida da personagem principal, o negro Amaro.

Por se tratar de uma obra que se filia à estética naturalista c evidente a tendéncia a considerar, dentro dos postulados da escola. o ambiente social como condicionador das condutas humanas, avultando neste sentido o problema da perversāo sexual entre os marinheiros, tese que é defendida de forma convincente, através da valorização total do ambiente, elemento literário da descriçāo.

O narrado está diretamente vinculado à especialização; c ao abolir de todo o aspecto ornamental para se tornar significativa, a descriçāo dá ao espaço um sentido integralizador, ligando-o intimamente às experiências humanas, numa relação evidenciada de causa e efeito. o espaço tornando-se ao mesmo tempo signo, índice e agente propulsor das condutas humanas.

\section{Riassunto *}

Questo lavoro riguarda lo studio dello spazio nell/opera Bom Crloulo, di Adolfo Caminha. col tentativo di dimostrare la sua oggettività e funzionalitá. Sono stati così considerati tre spazi forti: le imbarcazioni. la palazzina della Via della Misericordia e l'ospedale, i quali funzionano come delimitatori e elementi decisivi nella vita del personaggio principale, il negro Amaro. 
Trattandosi di un'opera che si affilia all'estetica naturalista é evidente la tendenza nel considerare, dentro i postulati della scuola. l'ambiente sociale come condizionatore del comportamento umano, dando rilicvo, in questo senso, al problema della pervesione sessuale tra $\mathrm{i}$ marinai, in una tesi che è difesa in modo convincente, attraverso la valorizzazione totale dell'ambiente, elemento letterario della descrizione.

La narrativa è direttamente vincolata alla spazialità; e abolendo completamente l'aspetto ornamentale, per farsi significativa, la descrizione dà allo spazio un valore integralista, legandolo intimamente all'esperienza umana, in un evidente rapporto di causa e effetto. diventando lo spazio allo stesso tempo segno, indice e agente propulsorio del comportamento umano.

* Versāo da professora Carolina Massi Albanese 